\title{
Transient tachypnoea of the newborn and asthma
}

\author{
M SHOHAT, G LEVY, I LEVY, T SCHONFELD, AND P MERLOB* \\ Department of Pediatrics ' $A$ ' and the *Neonatal Department, Beilinson Medical Center, Petah Tiqva and the \\ Sackler School of Medicine, Tel Aviv University, Israel
}

SUMMARY A total of 58 children aged $4-5$ years who were diagnosed as having transient tachypnoea of the newborn were studied. In contrast with the control group $(n=58)$, the infants with transient tachypnoea of the newborn had a significantly higher incidence of recurrent (more than two) episodes of wheezy breathlessness, symptoms consistent with asthma, and signs consistent with atopy.

Since initially described by Avery et al in $1966,{ }^{1}$ transient tachypnoea of the newborn has been considered a transitory respiratory disturbance resulting from a delay in alveolar fluid resorption. ${ }^{2}$ To our knowledge, there is no controlled data regarding long term follow up of late respiratory sequelae of infants with this condition. The purpose of this study was to examine the possible relationship between transient tachypnoea of the newborn and the incidence of respiratory diseases, especially childhood asthma, during infancy.

\section{Patients and methods}

Over the three year period from January 1980 to December 1982, 12049 neonates of gestational age $\geqslant 34$ weeks and birth weight $>2000 \mathrm{~g}$ were born at the Beilinson Medical Center, Petah Tiqva, Israel. Sixty seven of these $(0.6 \%)$ were diagnosed as having transient tachypnoea of the newborn. The diagnosis was based on the following clinical and laboratory criteria:

(1) Onset of tachypnoea (respiratory rate exceeding 60/minute) within six hours after birth.

(2) Persistence of tachypnoea for at least 12 hours.

(3) A chest radiograph in the first 24 hours that showed at least one of the following four findings: prominent central vascular markings, widened interlobar fissures of pleural fluid, symmetrical perihilar congestion, hyperaeration as evidenced by flattening, and depression of the diaphragmatic domes or increased anteroposterior diameter, or both. ${ }^{1}$
(4) Absence of hypercapnoea (that is, a $\mathrm{PaCO}_{2}$ $>6.00 \mathrm{kPa}$ ) and no need for assisted ventilation.

(5) Exclusion of all other known causes of respiratory distress syndrome.

A control group $(n=67)$ was selected consisting of the first neonate who was born immediately after a neonate in the group with transient tachypnoea of the newborn who had the same birth weight and similar gestational age and who showed no evidence of respiratory symptoms after birth. All clinical data including pregnancy, labour, and perinatal status were collected retrospectively from the infants' hospital records.

Two physicians (GL and MS) visited the 134 infants of both the study and the control groups at their homes. All the children were 4-5 years of age when visited. The physicians were not aware as to which group the infants belonged. One hundred and sixteen families out of 134 were located, 58 in each group. The mothers were asked to provide the following information: (a) history of atopy (hay fever, asthma, atopic dermatitis) in first degree relatives; (b) other diseases in the family; (c) frequency and nature of symptomatic episodes consistent with asthma in the infant studied including wheezing, dyspnoea, and persistent cough; (d) treatment with bronchodilators and their effect; (e) any time spent in hospital or visits to the emergency room for that reason; and (f) any evaluation or follow up in asthma clinics. The same information was elicited for symptoms related to laryngitis, pharyngitis, upper respiratory tract infections, pneumonia (proved by chest radiography), or any other diseases.

For evaluating the data we divided the children into two subgroups. The first group were those with 'confirmed' asthma - that is, children who had more than two episodes of dyspnoea, whose wheezing improved by bronchodilator treatment (with or without antiasthmatic prophylactic treatment, and where the diagnosis of asthma was confirmed after hospital evaluation. The second group were those with 'suspected' asthma - that is, children who had more than two episodes of dyspnoea, who wheezed, and who were diagnosed as suffering from possible asthma (either bronchodilator treatment was not 
given or there was no effect on bronchodilators when given in children younger than 2 years old).

Numerical data from the two groups were compared using the $\chi^{2}$ test for statistical evaluation.

\section{Results}

The group with transient tachypnoea of the newborn and the controls were comparable for gestational age, birth weight, and other perinatal conditions (table 1). The infants' medical histories, as provided by the mothers, are summarised in table 2 . Infants with transient tachypnoea of the newborn had a significantly higher incidence of recurrent (more than two) episodes of wheezy breathlessness ('confirmed' or 'suspected' asthma) (17 compared with six, $\mathrm{p}<\cdot 02)$. Symptoms consistent with childhood

Table 1 Perinatal data for the study and control groups

\begin{tabular}{|c|c|c|}
\hline & $\begin{array}{l}\text { Group with } \\
\text { transient tachypnoea } \\
\text { of the newborn } \\
(n=58)\end{array}$ & $\begin{array}{l}\text { Controls } \\
(n=58)\end{array}$ \\
\hline \multicolumn{3}{|l|}{ Gestational age (weeks): } \\
\hline 34 & 4 & 3 \\
\hline 35 & 6 & 5 \\
\hline$\geqslant 36$ & 48 & 50 \\
\hline \multicolumn{3}{|l|}{ Low birth weight } \\
\hline$(2000-2499 \mathrm{~g}):$ & 10 & 8 \\
\hline Large for gestational age & 3 & 0 \\
\hline \multicolumn{3}{|l|}{ Sex: } \\
\hline Male & 32 & 21 \\
\hline Female & 26 & 37 \\
\hline \multicolumn{3}{|l|}{ Mode of delivery: } \\
\hline Caesarean & 11] & 7) \\
\hline Breech extraction & $4\} 21$ & 317 \\
\hline Forceps & $6]$ & 7) \\
\hline
\end{tabular}

Table 2 Medical histories of the study and control groups

\begin{tabular}{|c|c|c|c|}
\hline & $\begin{array}{l}\text { Group with } \\
\text { transient } \\
\text { tachypnoea of } \\
\text { the newborn } \\
(n=58)\end{array}$ & $\begin{array}{l}\text { Controls } \\
(n=58)\end{array}$ & p Value \\
\hline \multicolumn{4}{|c|}{$\begin{array}{l}\text { No of infants with a history of: } \\
\text { Asthma: }\end{array}$} \\
\hline 'Confirmed' & 6 & 0 & 0.026 \\
\hline 'Suspected' & 11 & 6 & - \\
\hline Both & 17 & 6 & 0.02 \\
\hline Other atopic symptoms & 6 & 0 & $0 \cdot 02$ \\
\hline Positive atopy in family & 23 & 13 & 0.07 \\
\hline Pneumonia & 8 & 4 & - \\
\hline \multicolumn{4}{|l|}{$\begin{array}{l}\text { Recurrent upper respiratory } \\
\text { tract infections }(>2\end{array}$} \\
\hline Other non-respiratory & & & \\
\hline complaints & 12 & 13 & - \\
\hline
\end{tabular}

asthma and other atopic conditions were also more common (six compared with none, $\mathrm{p}<0.03$ ). Family history of atopy (23 compared with 13) and other respiratory problems were also more frequent in the study group, but this was not significant (table 2). Non-respiratory complaints were of equal frequency in both groups.

\section{Discussion}

In our study population of children aged less than 6 years, it was impossible to confirm the diagnosis of asthma by physiological studies of airflow obstruction. Therefore, our diagnosis was based on history, clinical findings, and the response to bronchodilators. Infants who had transient tachypnoea of the newborn suffered from significantly more recurrent dyspnoeic episodes consistent with childhood asthma than did the infants in the control group.

The medical history of the children in this study was obtained from the mothers of both groups. Because mothers in Israel tend to consult a variety of sources for the medical care of dyspnoea (emergency room, family physicians, consultant physicians), direct interviewing was the most feasible method of data collection. Indeed the fact that only one out of the 116 children in the study had more than two episodes of upper respiratory tract infection annually may reflect a recall problem. As a check on potential recall bias, however, each mother in both groups was asked to list other respiratory and non-respiratory problems in her child's medical history. Although infants with transient tachypnoea of the newborn did not have significantly more episodes of other respiratory diseases, they did have significantly more atopy other than asthma (hay fever and atopic dermatitis). This is in agreement with the previous findings of high incidence of atopic diseases in children with asthma. ${ }^{3}$

The fetal lung fluid is normally absorbed before and during delivery; and a delay in this 'major physiological event' is the cause of transient tachypnoea of the newborn. ${ }^{12}$ The clearance of the fluid depends on three mechanisms of removal: (1) squeezing of the thorax in the birth canal; caesarean delivery eliminates the 'pelvic squeeze' and is, therefore, a risk factor for the development of transient tachypnoea of the newborn. (2) The absorption of fluid through the interstitial tissue to the pulmonary lymphatics and capillaries. (3) Cessation of fluid secretion by the pneumocytes as a response to the pronounced increase in the release of catecholamines in the newborn. ${ }^{4}$ Prematurity, which consists of incomplete development of the beta adrenergic system, is known to be a risk factor 
for the development of transient tachypnoea of the newborn.

Recent studies indeed showed the beta adrenergic system as having an important role in the increased fluid absorption as well as the decreased fluid production occurring after birth. ${ }^{5}$ In addition, a relationship between asthma and beta adrenergic system malfunction was suggested by the reduction in the number of lymphocytic beta adrenoreceptors in bronchial asthma causing overall subsensitivity in this system. This appears to be fundamentally characteristic of atopy and is associated with a concurrent increase in alpha ${ }_{2}$ adrenergic receptors. The degree of reduction in the lymphocytic beta receptor number correlates well with the disease severity and airway obstruction. ${ }^{6}$ Therefore, beta adrenergic malfunction, which is associated with both delayed fluid reabsorption in the newborn and asthma, may be one of the common pathogenic mechanisms.

In this retrospective study mothers were interviewed in order to obtain the maximum information possible regarding the incidence of symptoms suggestive of childhood asthma. Our study suggests that there is a significant increase in the incidence of childhood asthma in infants with transient tachypnoea of the newborn. A prospective study will be helpful in further establishing this relationship, as well as their association to the beta adrenergic system malfunction.

We gratefully acknowledge Drs M Nitzan, SH Reisner, and C Springer for their help and important comments. We thank Daune Thorington for her excellent secretarial help. This work was supported in part by Shriber Fund, Sackler School of Medicine, Tel Aviv University, Israel.

This work was submitted as part of the requirements for the MD degree of Dr G Levy.

\section{References \\ 1 Avery ME, Gatewood OB, Brumley G. Transient tachypnea of newborn, possible delayed resorption of fluid at birth. Am J Dis Child 1966;111:380-5. \\ 2 Rimmer S, Fawcitt J. Delayed clearance of pulmonary fluid in the neonate. Arch Dis Child 1982;57:63-7. \\ ${ }^{3}$ Shohat M. Diagnosis, management, and prognosis of asthma in children. Comprehensive Therapy 1987;13:7-13. \\ ${ }^{4}$ Lagercrantz H, Bistoletti P. Catecholamine release in the newborn infant at birth. Pediatr Res 1973;11:889. \\ ${ }^{5}$ Wyszogrodski I, Taeusch HW Jr, Avery ME. Isoxuprine- induced alterations of pulmonary pressure-volume relationships in premature rabbits. Am J Obstet Gynecol 1974;119:1107. \\ ${ }^{6}$ Barnes PJ. Endogenous catacholamines and asthma. J Allergy Clin Immunol 1986;77:791-5.}

Correspondence to Dr M Shohat, Department of Pediatrics, Cedars-Sinai Medical Center, 8700 Beverly Boulevard, Los Angeles, CA 90048, USA.

Accepted 16 August 1988

\title{
Evaluation of two combined oxygen and carbon dioxide transcutaneous sensors
}

\author{
H K LEE, E BROADHURST, AND P HELMS \\ Respiratory Unit, Hospital for Sick Children, Great Ormond Street, London
}

SUMMARY Two combined oxygen and carbon dioxide electrodes were assessed in neonates, infants, and children up to 16 years. They were convenient to use and the measurement error for $\mathrm{PtcCO}_{2}$ was acceptable. In both models, however, the $\mathrm{PtcO}_{2}$ electrode had a reduced performance compared with a single electrode.

Transcutaneous measurements of oxygen and carbon dioxide $\left(\mathrm{PtcO}_{2}, \mathrm{PtcCO}_{2}\right)$ are useful in the intensive care unit because they provide continuous and non-invasive monitoring of gas exchange. $\mathrm{PtcO}_{2}$ underestimates arterial oxygen $\left(\mathrm{PaO}_{2}\right)$ because of the skin diffusion barrier and $\mathrm{PtcCO}_{2}$ overestimates arterial carbon dioxide $\left(\mathrm{PaCO}_{2}\right)$ because of skin carbon dioxide production. ${ }^{1}$ Various methods of 'arterialising' $\mathrm{PtcO}_{2}$ and $\mathrm{PtcCO}_{2}$ by appropriate adjustment at calibration have been described..$^{2-4}$

Until recently, $\mathrm{PtcO}_{2}$ and $\mathrm{PtcCO}_{2}$ sensors consisted of two electrodes that were each calibrated and applied separately. The introduction of combined oxygen and carbon dioxide electrodes in a single probe has obvious advantages, and previous reports in newborn infants ${ }^{5}$ and adults ${ }^{6}$ have suggested an accuracy comparable with separate oxygen and carbon dioxide electrodes.

We therefore assessed two commercially available combined oxygen and carbon dioxide electrodes in infants and children beyond the neonatal period using calibration correction factors obtained from previous studies with single electrodes. ${ }^{34}$ 